\title{
RESEARCH ON QUALITY CONTROL METHOD OF LAND COVER CLASSIFICATION DATA ORIENTED TO NATIONAL GEOGRAPHIC CONDITION MONITORING
}

\author{
Wenjuan Mao ${ }^{1, *}$, Haitao Zhao ${ }^{1}$, Wenchao Gao ${ }^{1}$, Hongjing Tu ${ }^{1}$, Yongmin $\mathrm{Xu}^{1}$ \\ ${ }^{1}$ National Quality Inspection and Testing Center for Surveying and Mapping Products, Beijing, China - 67516521@qq.com
}

Commission III, ICWG III/IVb

KEY WORDS: Land Cover Classification Data, National Geographical Condition Monitoring, Quality control.

\begin{abstract}
:
Aiming at the quality problems of the land cover classification data, such as missing update of changed spots, overrun of spot collection accuracy, incorrect spot classification, and inconsistencies between the filling of the change types of map spots and technical regulations, had been found during the quality inspection of the national geographic condition monitoring in China. This paper analyzed the key production factors, processes and causes that affect the process quality of the land cover classification data, and proposed the concept of the whole production quality control, and discussed the quality control measures to improve the land cover classification product. The research based on the new requirements of the whole-process quality control system in order to solve the quality problem-oriented production quality control method, could improve the quality of land cover classification product and provided reference for the quality control of the production process of related engineering projects in the future.
\end{abstract}

\section{INTRODUCTION}

The fundamental geographic national condition monitoring uses high-resolution aerial and aerospace remote sensing images to produce digital orthophoto images, land cover classification, geographical and national conditions, databases, statistical analysis and other results to monitor land changes within China's territory, the cycle is once a year (Gao, 2020). At present, the achievements have been applied in the fields of natural resource management, environmental protection and governance, people's livelihood guarantee, emergency disaster relief, and so on. Land cover classification data is one of the most important products in the national geographic condition monitoring (Zhang, 2016). The quality of the results directly affects the authority, objectivity and accuracy of the final monitoring products. Due to China's vast territory, the complexity and diversity of land cover classification content and the variety of geographical phenomena, and as an innovative achievement, its form, content and technical requirements are novel. Due to the existing technical conditions, there are inevitably quality errors in the achievements. This paper discussed the problems, causes and countermeasures of affecting the quality of land cover classification data, and put forward the quality control methods of land cover classification data.

\section{DATA CONTENT}

The land cover classification data mainly uses the images obtained in the second quarter of the current year as the main image data source. Through the comparison with the image data used in the monitoring results of the previous year, the change map patches are found, and the version data of the current year's surface coverage classification results is formed through the operations of change information extraction, field investigation and verification, and interior editing and sorting (Chen, 2012). The production and quality control process of land cover classification data is shown in Figure 1.

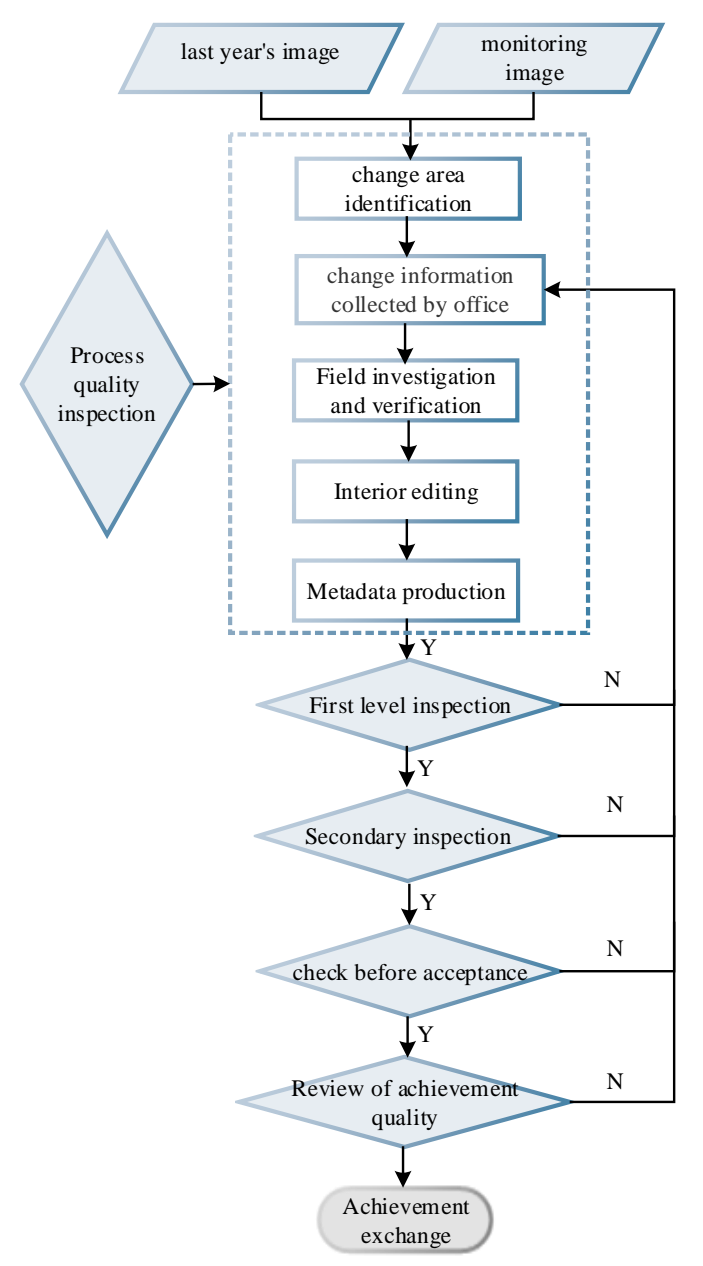

Figure 1. Production and Quality Control Process of Land Cover Classification Data

* Corresponding author 
The classification information of land cover reflects the natural attributes or conditions of natural and artificial buildings. These lands may be classified 8 one-class types, 53 second-class types and 107 third-class types, which provide a foundation to further research, as shown in Table 1.

\begin{tabular}{|c|c|c|c|}
\hline $\begin{array}{c}\text { Classification } \\
\text { code }\end{array}$ & One-class type & $\begin{array}{c}\text { Number } \\
\text { of 2nd- } \\
\text { class types }\end{array}$ & $\begin{array}{c}\text { Number of } \\
\text { 3rd-class } \\
\text { types }\end{array}$ \\
\hline 0100 & Planting land & 9 & 13 \\
\hline 0300 & Forest and grass & 11 & 22 \\
\hline 0500 & Constructions & 5 & 10 \\
\hline 0600 & $\begin{array}{c}\text { Railway and } \\
\text { road }\end{array}$ & 5 & 5 \\
\hline 0700 & Structure & 9 & 30 \\
\hline 0800 & Artificial piling & 4 & 14 \\
\hline 0900 & Bare surface & 5 & 5 \\
\hline 1000 & Waters & 5 & 8 \\
\hline
\end{tabular}

Table 1. Classification of monitoring contents

\section{QUALITY CONTROL}

\subsection{Quality control methods and process}

In order to ensure the overall quality "comprehensive, real and accurate" of the land cover classification data, based on the implementation of two-level inspection and one-level acceptance quality control mode for land cover classification data, this paper put forward the quality control measures of process quality inspection and random inspection, as well as the review of the achievements after acceptance, and put forward the quality control method and process for land cover coverage classification data, as shown in figure 1.

In order to ensure the authenticity, accuracy and reliability of the land cover classification data, through the whole process of the quality control, the key elements such as image source, technology and process affecting the quality of land cover classification data were controlled, and it was found and solved the quality problems in production are found and solved in time. The method of "prevention first and combination of prevention and inspection" was adopted to eliminate the hidden quality problems in the production process.

Through the review of the data results of the land cover classification acceptance of the provincial responsible achievements, the consistency of the acceptance scale and the accuracy of the quality evaluation conclusion were ensured.

\subsection{Quality evaluation}

Based on the full consideration of data production, quality control and results characteristics, the quality elements, inspection items, technical requirement and qualification conditions for the quality evaluation of land cover classification data were formulated, as shown in Table 2.

\begin{tabular}{|c|c|c|c|c|c|}
\hline Quality elements & $\begin{array}{c}\text { Quality sub } \\
\text { elements }\end{array}$ & Inspection items & $\begin{array}{l}\text { Inspection } \\
\text { results }\end{array}$ & $\begin{array}{l}\text { Technical } \\
\text { requirement }\end{array}$ & $\begin{array}{l}\text { Qualification } \\
\text { conditions }\end{array}$ \\
\hline \multirow{3}{*}{$\begin{array}{c}\text { Spatial reference } \\
\text { system }\end{array}$} & geodetic datum & coordinate system & \multirow{3}{*}{$\begin{array}{l}\text { conformity/ } \\
\text { inconformity }\end{array}$} & \multirow{3}{*}{$\begin{array}{l}\text { according to the } \\
\text { technical design }\end{array}$} & \multirow{3}{*}{ conformity } \\
\hline & elevation datum & elevation datum & & & \\
\hline & map projection & projection parameters & & & \\
\hline \multirow{2}{*}{ Time accuracy } & \multirow{2}{*}{ current situation } & source & \multirow{2}{*}{$\begin{array}{l}\text { conformity/ } \\
\text { inconformity }\end{array}$} & \multirow{2}{*}{$\begin{array}{l}\text { according to the } \\
\text { technical design }\end{array}$} & \multirow{2}{*}{ conformity } \\
\hline & & results & & & \\
\hline \multirow{8}{*}{$\begin{array}{l}\text { Logical } \\
\text { consistency }\end{array}$} & \multirow{2}{*}{ conceptual consistency } & property item & \multirow{2}{*}{$\begin{array}{l}\text { conformity/ } \\
\text { inconformity }\end{array}$} & \multirow{2}{*}{$\begin{array}{l}\text { according to the } \\
\text { technical design }\end{array}$} & \multirow{2}{*}{ conformity } \\
\hline & & data set & & & \\
\hline & \multirow{3}{*}{ format consistency } & data format & \multirow{3}{*}{$\begin{array}{l}\text { conformity/ } \\
\text { inconformity }\end{array}$} & \multirow{3}{*}{$\begin{array}{l}\text { according to the } \\
\text { technical design }\end{array}$} & \multirow{3}{*}{ conformity } \\
\hline & & data file & & & \\
\hline & & file naming & & & \\
\hline & \multirow{3}{*}{$\begin{array}{l}\text { topological } \\
\text { consistency }\end{array}$} & gap & \multirow{2}{*}{$\begin{array}{l}\text { conformity/ } \\
\text { inconformity }\end{array}$} & \multirow{2}{*}{$\begin{array}{l}\text { according to the } \\
\text { technical design }\end{array}$} & \multirow{2}{*}{ conformity } \\
\hline & & overlap & & & \\
\hline & & continuity & $\mathrm{r}=\mathrm{n} / \mathrm{N} \times 100 \%$ & $\mathrm{r} 0=0.3 \%$ & $\mathrm{r} \leq \mathrm{r}_{0}$ \\
\hline \multirow{2}{*}{$\begin{array}{c}\text { Acquisition } \\
\text { accuracy }\end{array}$} & \multirow{2}{*}{ plane accuracy } & geometric displacement & \multirow{2}{*}{$\mathrm{r}=\mathrm{n} / \mathrm{N} \times 100 \%$} & \multirow{2}{*}{$\mathrm{r}_{0}=0.3 \%$} & \multirow{2}{*}{$\mathrm{r} \leq \mathrm{r}_{0}$} \\
\hline & & vector join & & & \\
\hline \multirow{2}{*}{$\begin{array}{l}\text { Classification } \\
\text { accuracy }\end{array}$} & $\begin{array}{c}\text { classification } \\
\text { correctness }\end{array}$ & $\begin{array}{c}\text { classification code } \\
\text { value }\end{array}$ & \multirow{2}{*}{$\mathrm{r}=\mathrm{n} / \mathrm{N} \times 100 \%$} & \multirow{2}{*}{$\begin{array}{c}\text { key elements: } \\
\mathrm{r}_{0}=0.1 \% \\
\text { General elements: } \\
\mathrm{r}_{0}=0.4 \%\end{array}$} & \multirow{2}{*}{$\mathrm{r} \leq \mathrm{r}_{0}$} \\
\hline & Integrity & integrity & & & \\
\hline $\begin{array}{l}\text { Attribute } \\
\text { precision }\end{array}$ & attribute correctness & property value & $\mathrm{r}=\mathrm{n} / \mathrm{N} \times 100 \%$ & $\mathrm{r}_{0}=0.4 \%$ & $\mathrm{r} \leq \mathrm{r}_{0}$ \\
\hline $\begin{array}{c}\text { Characterization } \\
\text { quality }\end{array}$ & $\begin{array}{c}\text { geometric } \\
\text { representation }\end{array}$ & geometric anomaly & $\mathrm{r}=\mathrm{n} / \mathrm{N} \times 100 \%$ & $\mathrm{r}_{0}=0.4 \%$ & $\mathrm{r} \leq \mathrm{r}_{0}$ \\
\hline
\end{tabular}

Table 2. Quality evaluation index of land cover classification data.

\section{MAIN QUALITY PROBLEMS AND TREATMENT}

\subsection{Acquisition accuracy}

The accuracy of data acquisition is the corresponding degree between the boundary and position of the collected features and the boundary and position of the features on the image. Generally, the acquisition accuracy of the boundary of land cover classification should be controlled within 5 pixels.
The difference between the collection accuracy and the patch information collection during the geographical condition survey was that the production of land cover classification data of geographical conditions monitoring focused on the identification and collection of map patches in the changed areas, and the errors of changing patch boundary and image registration exceeding the limit mainly focus on the insufficient updating of change patches. During the production, the operators should not only pay attention to the update of 
classification code, but also check whether there were other places which were not updated in place. At the same time, It was checked whether there was an error that the local patch edge line and the digital orthophoto map exceed the limit due to mis-operation.

\subsection{Classification accuracy}

1) Overall quality issues related to the image source. The time point of geographic national conditions monitoring is June 30 every year (Chen, 2012). At the same time, due to the wide range of national monitoring area and the limited conditions for image acquisition in some monitoring areas, it is unable to meet the requirements of monitoring image coverage at one time, Therefore, the use of image data sources needs to be updated in time. Due to the improper use of images, there are obvious problems of missing update of image patches, e.g. Figure 2.

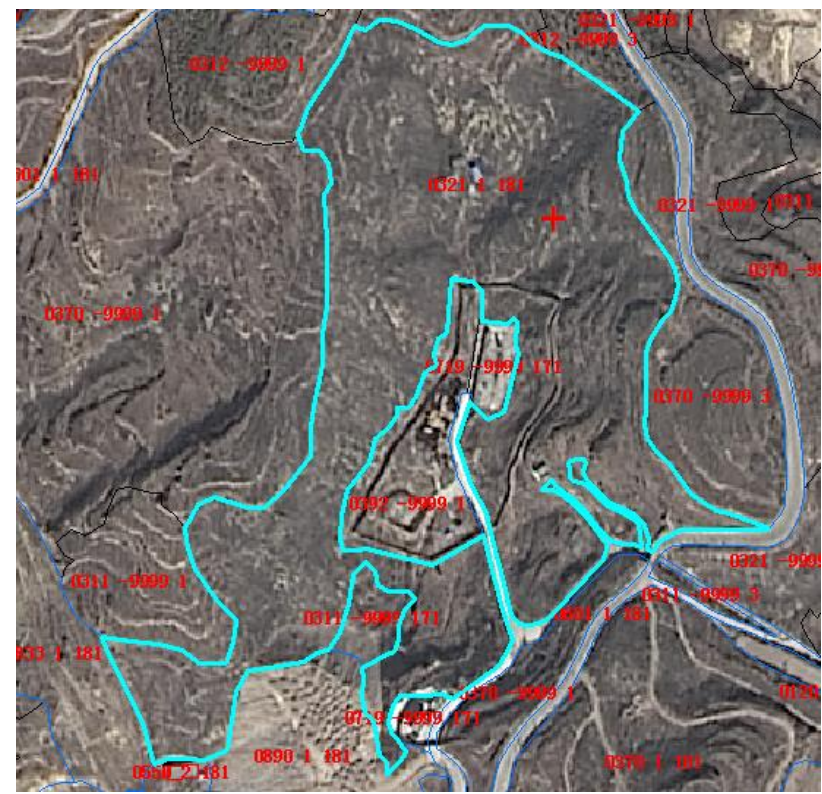

a) Remote sensing images of the first quarter.

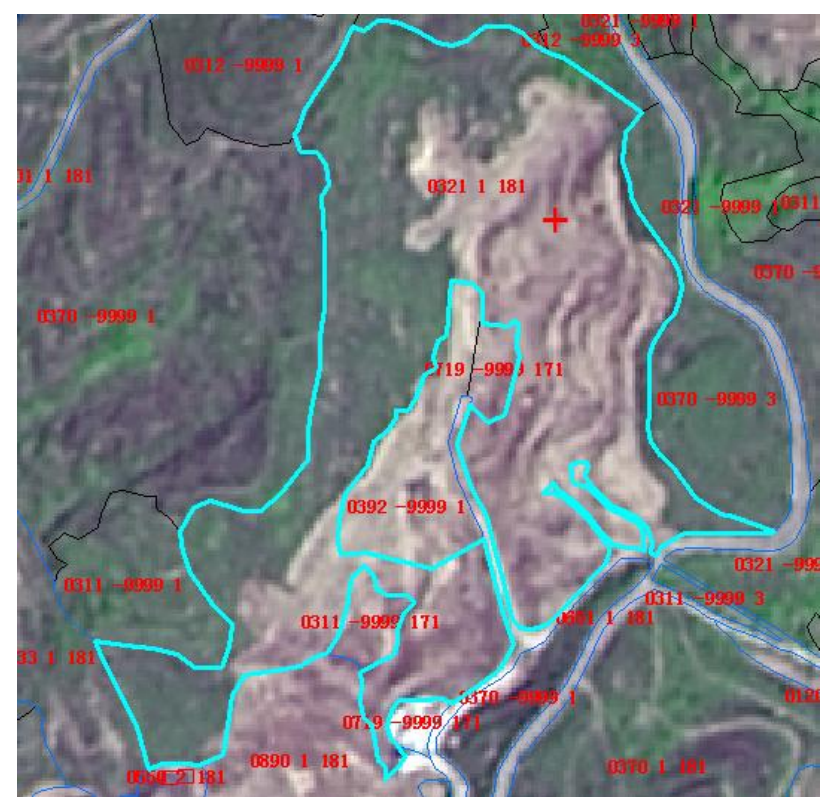

b) Remote sensing images of the second quarter.

Figure 2. Remote sensing images without the latest time phase
2) Missing updates. In the process of recognition and collection of change pattern information in monitoring period, it is not only required to identify the changes of frequent human activity areas, but also to implement different collection indicators for different regions. There are also omissions in building sites, demolition sites to be built, road construction sites, etc.; due to the lack of understanding of the technical requirements, the urban areas need to be updated; the image resolution is improved during the monitoring period, and the comprehensive large spots are not refined and updated; or the fast-growing economic forest such as eucalyptus planting with obvious local characteristics is omitted to be updated In addition, the data of land cover classification are not updated, e.g. Figure 3.

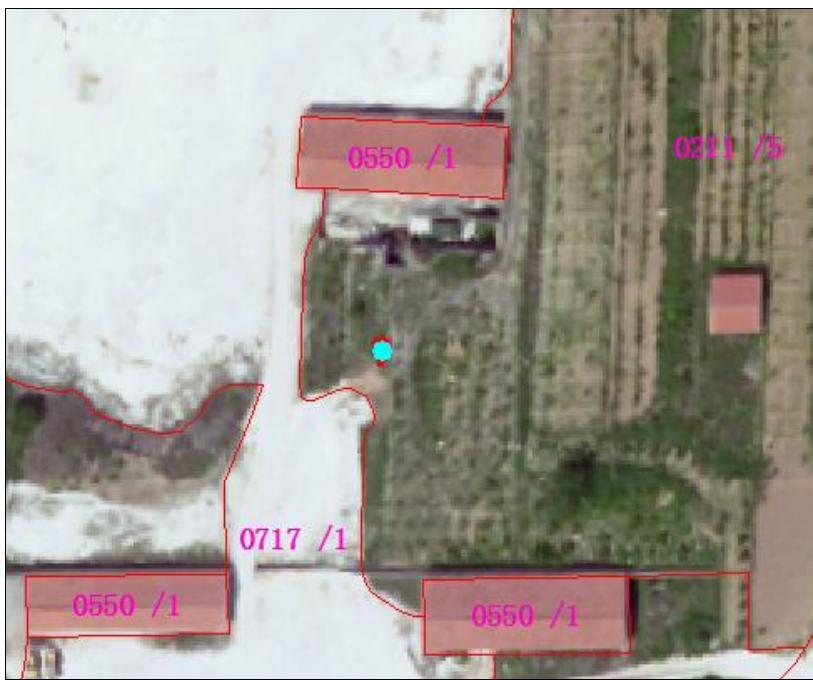

a) Remote sensing image and vector data of the previous year.

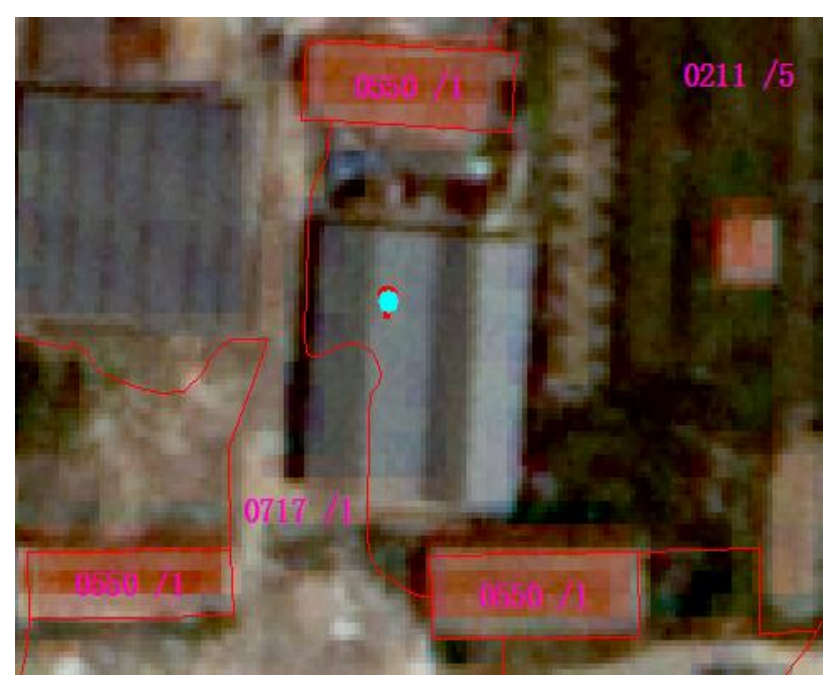

b) Remote sensing image and vector data.

Figure 3. Missing updates in housing construction area

3) Large patch error update. Due to the wrong operation in the process of patch cutting or merging, the wrong updating of large map patches without actual type change in the background is caused, such as large area dry map patch updating to building area or road, large area paddy field updating to water surface, etc., e.g. Figure 4. 


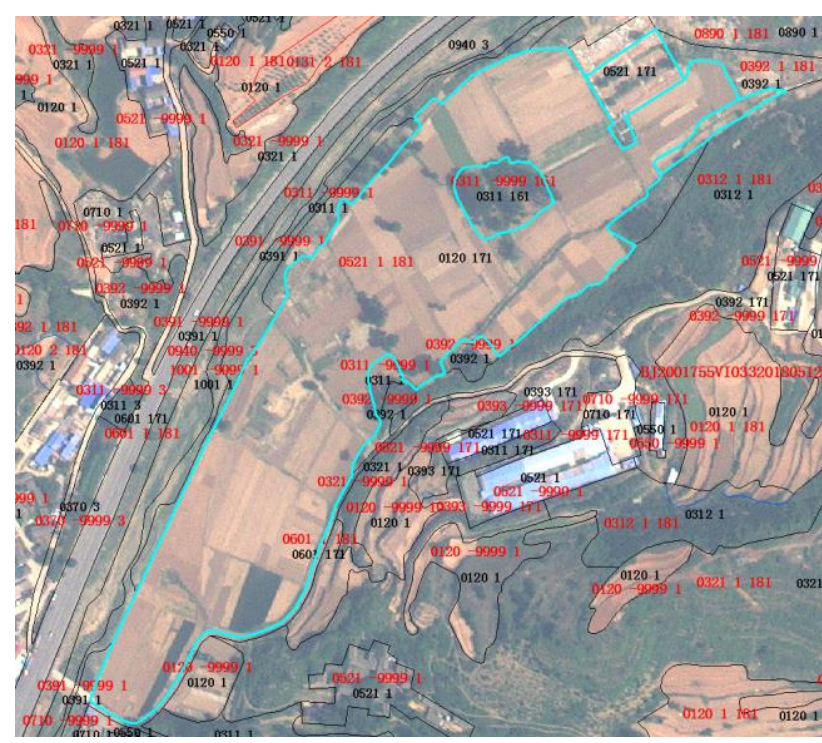

Figure 4. The dry land(0120) was incorrectly updated as a housing construction area(0521).

4) The patch classification code is inconsistent with the field investigation and verification results. The land cover classification data is related to the production mode of "office operation, field operation and office operation", so it is very important to effectively connect the internal and external industries. In the editing and sorting stage, if the classification code of field interpretation and field interpretation is inconsistent or the classification range of the patch is inconsistent, the field collection personnel should communicate timely to avoid the inconsistency of the classification code of the field collection, e.g. Figure 5.

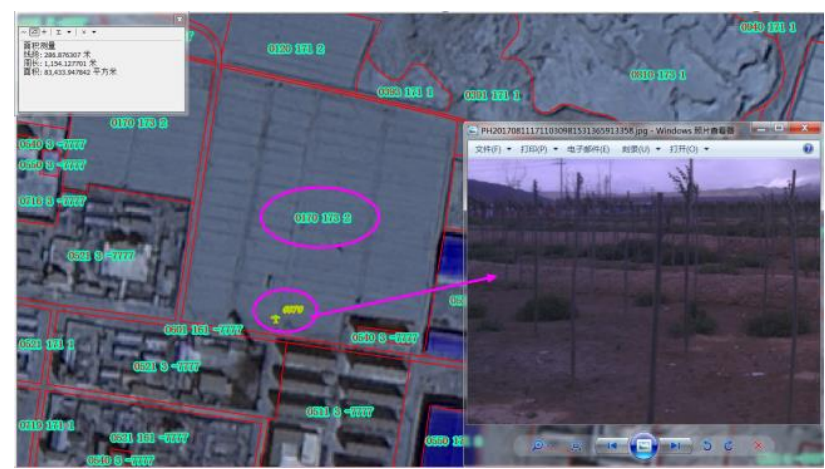

Figure 5. Field verification data is planted young forest (0370), but the results is expressed as nursery (0170).

5) The patch update error was caused by the lack of understanding of technical regulations. In the process of acquisition, due to the operators' misunderstanding of the definition of land type of land cover classification, inaccurate grasp of acquisition indicators, wrong way of image merging, inexperienced image interpretation, or not considering the environment around the patch in image interpretation, the land types with similar spectral characteristics were often updated back and forth. For example, the wrong acquisition of other construction sites was hard Changing the surface, removing the construction site to be built into waste dump, slope protection, irrigation and grass collection into hardened surface, coniferous forest and broad-leaved shrub forest are repeatedly updated, e.g. Figure 6.

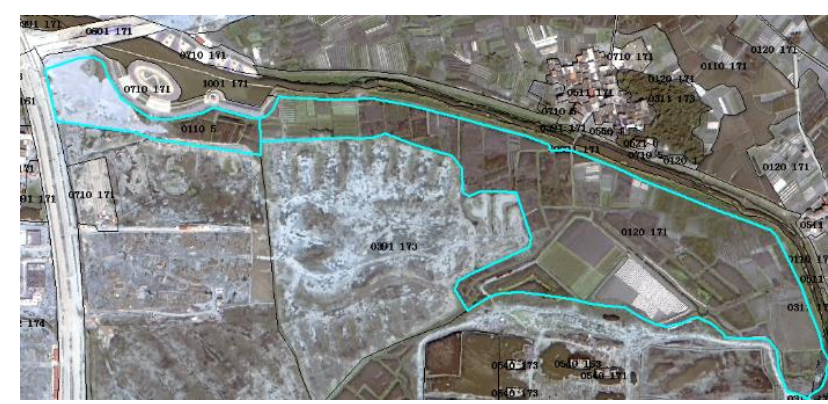

a) Remote sensing image and vector data of the previous year.

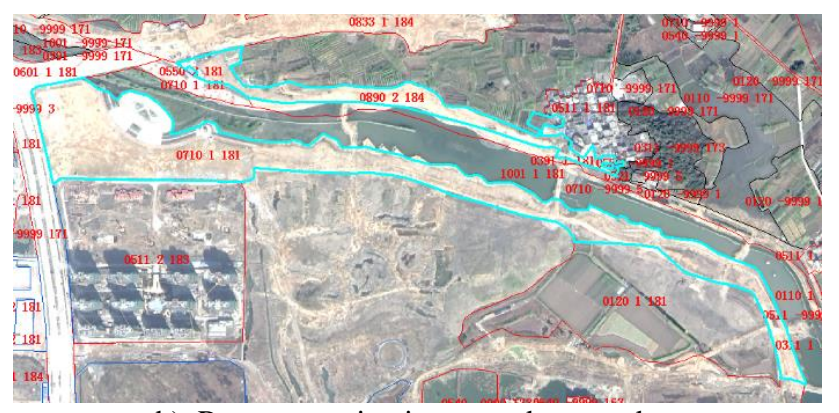

b) Remote sensing image and vector data

Figure 6. Other construction sites (0839) were mistakenly collected as hardened ground (0710) .

\subsection{Attribute precision}

The accuracy of the change type values can affect the results of statistical analysis of land cover classification data. When filling in the change type value of the change pattern patch, it is inevitable that the manual filling in the change type value will not take into account, and the value of the expansion change type will be wrongly filled in as the new type change type value, and the change type value of the change pattern patch will be omitted to update.

\subsection{Analyze the reasons}

In the monitoring of geographical conditions, the main reasons for the problems of land cover classification data can be summarized as the following three aspects.

1) Due to the lack of understanding of the change characteristics of the land type in the area and the inaccurate understanding of the collection requirements, some land types are repeatedly updated, and the land types meeting the index requirements in urban areas and the land types with similar spectrum are not updated correctly. At the same time, there is a lack of necessary field verification for the doubtful spots in the field interpretation. 2) Error of patch classification code caused by mis-operation. During the monitoring period, it is necessary to cut and merge the existing surface data, which is easy to produce extremely small surface, mis-operation and topology error; and the cost of troubleshooting is laborious, so it is urgent to increase the investment of scientific and technological forces.

3) Technical training and communication are insufficient or targeted. At present, geographical conditions monitoring has entered the normal working mode. The technical training and exchange of land cover classification data production should not be limited to basic and entry-level training. The training and exchange should be more targeted, and various forms of training and communication should run through the beginning and end of production. 


\subsection{Quality control measures}

Based on the above quality problems and cause analysis, it is necessary to strengthen the technical level, sense of responsibility and quality awareness of operators to ensure the quality of land cover classification data. Through targeted technical training and exchange, ensure correct understanding of work content and technical requirements; increase scientific and technological input, use tested software to assist production, and improve production efficiency, In order to reduce the interference of human factors on quality. Implement the concept of whole process quality control, carry out process quality inspection in each production link, find and solve quality problems in time, so as to ensure the quality control of land cover classification data achievements according to the unified scale and standard.

\section{CONCLUSION}

This paper discusses the quality control method of land cover classification data in geographical conditions monitoring, analyzes the main quality problems and causes, and applies the whole process quality control concept to the quality control of land cover classification data in geographical conditions monitoring. The quality is ensured by controlling the quality in key nodes of land cover classification production.

\section{REFERENCES}

Barsi, Á., Kugler, Z., Juhász, A., Szabó, G., Batini, C., Abdulmuttalib, H., Huang, G.M., Shen, H.F., 2019. Remote sensing data quality model: from data sources to lifecycle phases[J]. International Journal of Image and Data Fusion, 2019, 10:4, 280-299.

Chen, H.P., Cheng, P.F, Zhang, Li. 2017.Discuss on Specifications for Quality Evaluation of National Geographic Conditions Investigation Achievements. [J]. Geomatics \& Spatial Information Technology. 2017,40(1):43-45.

Chen, H.P., Zhang, L., Guo, J., Zhao, Y., Gao, W.C., 2018. Studies on Method of Quality Inspection for Land Cover Achievement. Geomatics \& Apatial Information Technology, 41(7), 72-74.

Chen, H.P., Zhang, Li, Zhao, Y.S., et al. 2018. Methods and practices of quality inspection of land cover classification product[J]. Science of Surveying and Mapping, 2018, 43(9):5862 .

Chen, J.Y., 2012.Study notes on geographic national condition monitoring [J]. Acta Geodaetica et Cartographica Sinica, 2012, 41(5):633-635.

Chen, Qing, Xu, Q.L., Li, W.W. Research on Fundamental Geographical Conditions Monitoring Techniques[J]. Geospatial Information, 2016, 14(2):10-13.

Cheng, P.F, Zhang, Li. 2015. Talking about the results of quality control of the national census from the quality review of the achievements[J]. China Surveying and Mapping, 2015(6):35-37.

Gao, W.C., Zhao, H.T., Mao, W.J., Yin, S., Tian, Z.B., 2020: Construction research and application of fundamental geographic national condition monitoring quality control system. International Archives of the Photogrammetry, Remote Sensing and Spatial Information Sciences - ISPRS Archives. doi.org/ 10.5194/isprs-archives-XLIII-B3-2020-1327-2020.

Gao, Z.H., Zhou, Xu, Cheng Tao. 2015. Statistical Analysis of the Confusing Land Cover Types in China Geography Census. [J]. Bulletin of Surveying and Mapping , 2015(6):32-34

Mao, W.J., Zhang, Li, Zhang, Lei, et al. 2017. Product quality inspection for geographical conditions element[J]. Science of Surveying and Mapping, 2017, 42(2):35-39.

Zhang, J.X. 2016. Thinking about Normalized Geographical Conditions Monitoring [J]. Geospatial Information, 2016, 14(4):1-3.

Zhang, L., Cheng, P.F., Han, W.L., 2015. Investigations of quality evaluation standard for national surveying and mapping key project produces. Bulletin of Surveying and Mapping, 2015(2), 55-57, 63. 